$\xi=-1$

\title{
Financial and Economic Safety: Formal Statement of the Task of Capital Flows Management
}

\author{
V.Ye. Likhtenshtein ${ }^{a}$, V.P. Los $^{a}$, G.V. Ross ${ }^{b}$, E.D. Tyshuk ${ }^{a}$ \\ a MIREA - Russian Technological University, Russia, Moscow \\ b Financial Management under the Government of the Russian Federation, Russia, Moscow
}

\begin{abstract}
The problem of global financial and economic security is considered. A substantive and formal formulation of the problem of capital flow modeling is formulated, based on two groups of theorems on economic management mechanisms: the planned mechanism and the market mechanism. The main characteristics of capital flow assessment are revealed.

This is an analysis of the situation in which it can be interpreted. The structure of the flow of water and the market mechanism were determined and proposed.
\end{abstract}

Keywords: financial-economical security management, the theory of equilibrium stochastic processes, the evolutionary simulation methodology, the instrumental system "Decision".

\section{Introduction}

The rapid development of financial technologies, infrastructure and openness of financial and economic systems in order to stimulate the economic growth of national economies has led to the fact that finances have broken away from the economic basis and began to play a fundamental role in socio-economic relations, intensifying the gap between material and financial flows. . The financial system and financial capital were transformed from intermediaries serving reproduction into key factors determining it [1-3].

These processes, on the one hand, are capable of giving a new powerful impetus to development [11], and on the other hand, due to the growing and increasing complexity of financial markets, lead to imbalances that become a source of threats to global instability, exacerbate critical contradictions in the economy, disrupt the reproduction process four]. The negative feedback of the financial system at the macro level transforms it from a tool to stimulate economic growth into a source of threats that could lead to the destruction of the existing socio-economic system.

Under these conditions, these contradictions can be interpreted as a problem of global financial and economic security (hereinafter FEB) [4]. The problem of the FEB economy has reached an uncontrollable level, characterized by systemic risks, social tension, which threatens the loss of controllability of the entire global financial and economic system. All this is fully reflected in the Russian economy, and the question of the need to find effective approaches to assessing indicators of financial and economic threats to capital flows between the main categories of economic agents (EA): households; firms; the state; foreign sector; as well as their prediction and the development of adequate methods to prevent them [6].

Under the FEB, we should understand the totality of the current state, conditions and factors characterizing the stability, sustainability and progressive development of EA, integrated into the economy of the Russian Federation. The FEB system is determined by the type, composition, values, limiting values of indicators of the socio-economic system, characterizing its security depending on the type, level and initial state. The main importance is not so much the current values of individual indicators used in the role of indicators, but the simultaneous achievement of threshold values by some of them, as well as a combination of trends in indicators. For example, for the financial collapse of the state is particularly dangerous combination of debt growth, decline in production and a decrease in investment. In this case, it is often resorted to investment by increasing public debt. This behavior is based on the expectation of income, but they may not be. This leads to the need to consider not one or several indicators, but to investigate them from a systemic point of view on mathematical models that allow one to comprehensively take into account the interrelations of all indicators [5, 12]. From the analysis of scientific sources it becomes clear that there is no shortage of quantity and variety of indicators. The problem is that any financial or economic indicator has a large, often unacceptably large information error. Among the sources of error, an important role belongs to financial bubbles and money laundering. In this case, the size of the error of a particular is estimated.

\section{Research Method}

Problems of the adequacy of existing and new indicators of threats to EA are associated with overcoming uncertainties and inaccuracies. One of the main means of solving this problem [3] is the use of economic-mathematical methods, in particular, evolutionary-simulation methodology (ECM) and Decision tool system.

The main ideas of capital flow modeling are based on two groups of theorems about the mechanisms of economic management: the planned mechanism (PM) and the market mechanism (RM) [6]. Theorems about PM in economics prove that with its long-term 
functioning all the flaws accumulate and sum up. There is a total shortage, imbalances, breakdowns of plans, inefficiency. In the end, the economy simply becomes unmanageable. And according to the theorems on the Republic of Moldova in the economy, its long-term functioning necessarily leads to the unlimited power of the oligarchy, inequality and inevitable collapse. Speaking about capital flows, we first need to clarify where and where capital can flow from, that is, between what objects flow occurs.

Taking into account risk $\mathrm{D}$, the average specific yield can be attributed to any class of capital: this is the sum of the products of income and their probabilities for the main types of operations characteristic of this class of capital for a given period of time divided by the average size of the operation. For example, the average specific income from one speculative operation has a certain probability of a successful outcome, that is, speculative operation will bring income, and not loss. Consider the main conclusions that follow from these theorems and relate to capital flows. Theorems reveal the content of capital movement mechanisms. Practical examples of switching from PM to PM and back are actually being put into practice, although not for the purposes of managing financial flows. RM is needed to identify real prices, supply and demand, the intentions of producers and consumers, and the allocation of resources. The $\mathrm{PM}$, in turn, allows the state to eliminate imbalances, destroy bubbles, and solve social and strategic tasks. The inclusion of PM is a tool of state intervention. To customize this tool and solve the question "When to interfere?", it is necessary to develop evolutionary-simulation models of PM, PM and EA.

\section{Resultsand Analysis}

For the formulation of the task, classes of capital are singled out. This is the capital with which this or that economic agent, or the capital used for a certain type of operations, for example, equity capital, production capital, financial capital, etc.operate. Let $\mathrm{j}=1, \ldots, \mathrm{J}$ be the number of a class of capital. Among the factors that determine the characteristics of any class of capital, you can distinguish the cost of a transaction with capital ( $\mathrm{f} 1, \mathrm{j}$ ), income from a transaction ( $f 2, j)$, the number of operations per unit of time (f3, j) In order to write down the simplest evolutionary-simulation model of a class of capital, we introduce the following quantities into consideration:

Faj is the expected demand for class $\mathrm{j}$ capital;

$P L j$ is the equilibrium volume of capital of class $j$;

$\mathrm{Cj}$-is income per ruble of investments (price) of class $\mathrm{j}$ capital;

$\mathrm{Sj}$ is the charge for using sources of financing when using capital of class $\mathrm{j}$ (cost price).

The ESM class of capital can be represented by a set of relations (1) - (5):

$$
\begin{aligned}
& F a_{j}=\rho_{j}\left(f_{1, j}, f_{2, j}, f_{3, j}\right) \\
& F_{1, j}=S_{j}\left(P L_{j}-F a_{j}\right), P L_{j} \geq F a_{j} \\
& F_{2, j}=\left(C_{j}-S_{j}\right)\left(F a_{j}-P L_{j}\right), P L_{j}<F a_{j} \\
& \min _{P L_{j}}\left\{\max _{\chi \in\{1,2\}}\left\{M\left\{F{ }_{\chi, j}\right\}\right\}\right\}
\end{aligned}
$$$$
P_{j}^{0}=P\left(P L_{j} \geq F a_{j}\right)
$$

\section{Wherein:}

- - imitational model of demand for capital of class $j$;

- - the costs of overstatement at excessive irrational investments;

- - underreporting costs with a lack of demand;

- - the expectation of the costs of overstatement (the risk of overstatement), when and the cost of underreporting (risk of underreporting) when;

- - the likelihood that the supply will be more demand;

- - the ratio of the risk of overvaluation to the risk of undervaluation.

The main characteristics $\{\mathrm{PLj}, 3 / 3 \mathrm{j}$,$\} belong to the capital of$ class $\mathrm{j}$. Consider two classes of capital $\mathrm{j}$ and $\mathrm{j}$ 'and $3 / 3 \mathrm{j}>3 / 3 \mathrm{j}$ '. In this case, there will be an overflow from class $j$ to class $j$ 'in the volume $V j, j$ ' $=P L j-P L ' j$, where $P L ' j$ is calculated using the model (1) - (5) for class $\mathrm{j}$ with the replacement $\mathrm{C} / 3 \mathrm{j}=3 / \mathrm{Hj}$ '. This is a consequence of the theorem, the essence of which is that with a sufficiently short period of time, the prevalence of the average specific yield in any of the market sectors leads to the accumulation of capital, but when another, most efficient investment sector appears, the direction of capital flow switches to it. If the prevalence of the average specific profitability with regard to risk remains constant for a long time on the same sector of the market, then disproportions arise and an oligarchy is created with all known negative consequences.

\section{Conclusion}

Management of capital flows is based on the implementation of tax innovations, procurement and commodity interventions, subsidies, subsidies, non-tariff regulation, fines, bonuses, legislative restrictions and other measures of government. The formal formulation of the problem allows one to formulate conditions for the transfer of capital between classes $j$ and $j$ ', and using the methodological foundations of capital management, to determine other integral characteristics of these processes.

\section{References}

[1] Abalkin L. Economic security of Russia: threats and their reflection // Voprosyekonomiki. 1994. N 12. S. 5 and others.

[2] Burtsev V.V. Factors of financial security of Russia // "Management in Russia and abroad" 2001. № 1

[3] Kaurova N.N. Financial and economic security in the context of openness of the national economy (theoretical and methodological aspect) // M .: 2013

[4] Kostyuk V.N. Financial bubbles and financial crises // Financial analytics: problems and solutions., 2012, №32, p. 2-11

[5] Lepeshkina MN Evolution of the concept of "economic security" in the United States, Western Europe and Russia // Economic Science and Practice: materials of the international scientific conference. Chita, Young Scientist Publishing House, 2012. - p. 7-9.

[6] Liechtenstein V.E., Ross G.V. Equilibrium random processes: theory, practice, infobusiness // Moscow: Finance and Statistics, 2015.

[7] Mau V. and others. Global crisis and trends in world development // Questions of economy, 11, 2014.

[8] Ross G.V. Modeling of production and socio-economic systems using the apparatus of combinatorial mathematics // M .: MIR, 2001

[9] Ross G.V., Liechtenstein V.E. Solving Russia's Economic Problems by Managing the Financial Bubbles of the Digital Economy // Economic and Human Sciences, №2 (312), 2018

[10] Senchagov V.K. Economic security of Russia (second edition) // Moscow: 2010

[11] Tolkachev S.A., Popov A.K. Formation of financial bubbles at the stage of growth of the economic system // Bulletin of Financial University, №2, 2015

[12] Labzunov P.P. Methodology of cost management of an industrial enterprise in modern society // Russian technological journal, № 2 (5), 2017, p. $70-77$ 